\title{
On the Sound Absorption Improvement of Water Hyacinth and Coconut Husk based Fiber Reinforced Polymer Panel
}

\author{
Erni Setyowati ${ }^{1}$, Iwan Yahya ${ }^{2,}$, Edi Supriyo ${ }^{3}$, Intan C. Romadhona ${ }^{2}$, Aris Minardi ${ }^{2}$ \\ ${ }^{1}$ Architecture Dept., Faculty of Engineering, Diponegoro University, Jl. Prof. Soedarto, SH, \\ Tembalang, Semarang \\ ${ }^{2}$ The Iwany Acoustics Research Group (iARG) Physic Dept, Sebelas Maret University, Jl. Ir. Sutami \\ 36A Kentingan, Solo \\ ${ }^{3}$ Chemical Engineering Dept., Vocational Faculty, Diponegoro University, Jl. Prof. Soedarto, SH, \\ Tembalang, Semarang
}

\begin{abstract}
This paper emphasizes on the sound absorption improvement of the water hyacinth and coconut husk based fiber reinforced polymer (FRP) panel. The dry water hyacinth and coconut husk were milled and sieved before it mixed with polyester and methyl ethyl ketone peroxide as the catalyst. The composition is $200 \mathrm{ml}, 25$ grams, and $20 \mathrm{ml}$ for the polyester, fiber, and catalyst respectively. The mixture casting is by using a square tray to form a flat FRP panel through open air drying without any compaction process. Three different approaches i.e. multiple quarter wavelength resonators, air cavity, and front fibrous layer inclusion are implemented to the FRP to improve its sound absorption performance. The entire measurements conducted by using transfer function based impedance tube technique refer to ASTM E-1050-98 standard. B\&K 4206. It found that the proposed approaches are increase sound absorption coefficient of the bulk FRP significantly. The best performance occurred on the coconut husk based FRP when the 8 of quarter wavelength resonators combined with the fibrous layer. Sound absorption increased accordingly to above of 0.7 starting from $1.5 \mathrm{kHz}$. On the other side, the air cavity shows similar influence on the entire test sample due to Helmholtz resonance mechanism.
\end{abstract}

\section{Introduction}

Indonesia is the world most coconut producing country. This plantation grown and cultivated in all islands over the country and used for many different purposes and applications. The entire parts of the plant bring valuable benefits for peoples ranging from foods, construction materials, drugs, home appliances, alternative energy resource, plantation media, and for packaging. Apart from its benefits, coconut husk is one of the plant valuable part was not yet optimally utilized.

\footnotetext{
Corresponding author: iyahya@mipa.iuns.ac.id
} 
Just like coconut husk, water hyacinths also grow in many lakes along the islands of Indonesia but not yet optimally utilized for creating valuable products. Currently, it used as raw materials for supply to handicraft and furniture industries. Even more, this plant causes serious environmental problems in many regions of the country.

According to its fibrous and porous structure, both coconut husk and water hyacinth are possible to use as sound absorbing materials. As reported in the literature, these two natural materials show a potential acoustical performance. Setyowati et al. have conducted experimental analysis for measuring the sound transmission loss and sound absorption coefficient of the materials. It found that the water hyacinths performs well at the range of frequency $2.5 \mathrm{kHz}$ to $3.25 \mathrm{kHz}$ with $57-59 \mathrm{~dB}$ of sound transmission loss, while the absorption coefficient of coconut husk based sample reaches the peak value of 0.9 at 2.5 $\mathrm{kHz}[1]$. The other research conducted by Fouladi et. al to compare the absorption coefficient of coconut fiber from the traditional market and industrial product made of coconut fiber with binder through analysis after Delaney-Bazley and Biot-Allard model. The absorption coefficient was successfully improved. The sound absorption coefficient shifted to a lower frequency band from $1.36 \mathrm{kHz}$ to $578 \mathrm{~Hz}$ as the thickness of the samples increased from $20 \mathrm{~mm}$ to $45 \mathrm{~mm}$ [2].

As for prediction purposes, Ramis et al. developed equations for prediction and simulation models of acoustics systems[3]. The other improvement approach such as air gap, fibrous material inclusion, and surface perforation conducted by Lee et al. and Zulkifli et al. [4], [5]. Previous work of Lee and Chen analyzed the improvement strategy of the multi layered sound absorbing material in regards to perforated plates, air spaces and porous materials[6]. The use of natural fibrous materials as the potential sound absorber also recommended by Ersoy and Kucuk, Mohanty et al. and Mueller \& Krobjilowski [7-9].

Even though the natural fibrous and porous materials have potential advantages, but most of them are not naturally compact and low in mechanical strength to use directly in noise control applications. According to this reason, researchers used several types of binder and additive substance to increase the mechanical strength and performance. This technique is running successfully but also resulting another constraint concerning the decrease of its acoustical performance. As the natural fibers mixed with any chemical or natural binder and then compacted through heating and or pressing technique, the materials becoming more stiff, harder, less porous and very reflected. This paper emphasized on the acoustical performance improvement strategy of the water hyacinth and coconut husk based fiber reinforced polymer (FRP) panel in regards to the use of quarter wavelength resonator, air cavity, and fibrous surface layer.

\section{The Object of Study}

The raw water hyacinth and coconut husk materials are collected from Rawa Pening lake and traditional market in Semarang respectively. After cleaning process, it dried in open air before milling and sieving steps. The dry water hyacinth and coconut husk fiber flour separately mixed with polyester as the binder and methyl ethyl ketone peroxide as the catalyst. Both have the same composition of $200 \mathrm{ml}$ polyester, 25 grams fiber, and $20 \mathrm{ml}$ catalyst. And as for the test sample preparation, the mixture casting was conducted by using a square shaped tray before it dried in open air for hardening purpose without compaction or pressing process. The resulting flat FRP were cut into some circularly shaped test sample sized $30 \mathrm{~mm}$ in diameter. Table (1) shows the detailed geometrical dimension and the treatment of the entire test samples. 
Table 1. The geometrical dimension and treatment of test samples

\begin{tabular}{|c|c|c|c|}
\hline Code & Material & Diameter & Thickness \\
\hline A & Water hyacinth & $30 \mathrm{~mm}$ & $15 \mathrm{~mm}$ \\
\hline B & & & $30 \mathrm{~mm}$ \\
\hline C & Coconut husk & & $15 \mathrm{~mm}$ \\
\hline D & & $30 \mathrm{~mm}$ \\
\hline \multicolumn{3}{|c|}{ Treatment code } \\
\hline H & Number of quarter wavelength resonators $(4,8,9)$ \\
\hline F & \multicolumn{2}{|c|}{ Foam front layer } \\
\hline Cav & \multicolumn{2}{|c|}{ Cavity (10 mm) } \\
\hline
\end{tabular}

\section{Methods}

The transfer function based two microphones impedance tube technique after ASTM E1050 conducted for measuring the sound absorption coefficient[10]. Each test samples treated with three different way as listed in Table (1). The small tube set up of the B\&K 4206 impedance tube used in the experiment with frequency span up to $6.4 \mathrm{kHz}$.

For investigation of resonator number influence on the sound absorption performance, the circular shaped FRP was drilled to form quarter wavelength resonator structure inside the specimens. In this case, there are three different number of the resonator as listed in Table (1). The first eight resonators have the same diameter of $3 \mathrm{~mm}$ while the 9 th is $8 \mathrm{~mm}$. For investigating of the back cavity and porous front layer impact, the experiment conducted with and without $10 \mathrm{~mm}$ cavity depth and $10 \mathrm{~mm}$ front layer. The front porous layer made of commercial Dacron layer. The test samples are illustrated in figure (1).

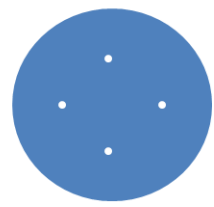

(a)

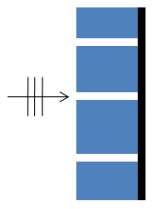

(b)

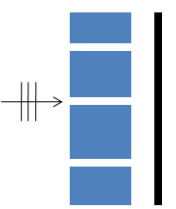

(c)

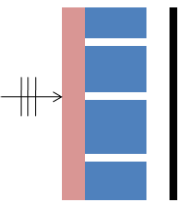

(d)

Fig. 1. The test sample top view (a) and configuration variations: (b). quarter wavelength resonator, (c). cavity backed FRP, and (d). cavity backe FRP with porous front layer.

The entire experiment is fully computer controlled where B\&K 4206 impedance tube connected to the four channels B\&K Pulse Analyzer LAN-XI type. The dedicated B\&K Material Testing Software used to control entire experiment steps. Random noise is generated from the loudspeaker of impedance tube and propagate along the tube before it hit the test sample surface. The two $1 / 4$ inch $4187 \mathrm{~B} \& \mathrm{~K}$ microphones capture both incidents and reflected wave before it decomposed by using transfer function analysis. Since the impedance tube assumed to be has an infinite impedance on the far end, energy decay is must be totally associated with the absorption performance of the test sample.

The frequency responce function $H_{12}$ and reflection coefficient $\mathrm{R}$ can be expressed as follows,

$$
H_{12}=\frac{P_{2}}{P_{1}}=\frac{e^{j k h}+e^{-j k h}}{e^{j k(h+s)}+e^{-j k(h+s)}}
$$


and

$$
R=\frac{H_{12}-e^{j k s}}{e^{j k s}-H_{12}} e^{j 2 k(h+s)}
$$

where $P_{1}$ and $P_{2}$ are sound pressure level captured by the two microphones in position one and two respectively. $k$ is wave number while $h$ and $\mathrm{s}$ are the distance from the first microphone to sample and the distance between microphones respectively. The coefficient absorption $\alpha$ can be calculated by:

$$
\alpha=1-[R]^{2}
$$

\section{Results and Discussion}

The influence of quarter wavelength resonator inclusion on the sound absorption performance illustrated in figure (2). Sound absorption performance of the entire four specimens before treatment is shown in figure (2a) while the treatment results depicted in figure (2b) and (2c). There is no significant improvement occurred according to thickness increment on the untreated water hyacinth based FRP, while the different phenomenon exists on the untreated coconut husk FRP. The untreated or bare water hyacinth FRP has the maximum sound absorption coefficient of 0.2 for the entire frequency range, while the coconut husk based FRP has the better performance with a maximum of 0.4 for the $15 \mathrm{~mm}$ thickness sample and 0.85 for the $30 \mathrm{~mm}$ sample. It occurred on frequency $1.7 \mathrm{kHz}$ and 2.8 $\mathrm{kHz}$ respectively.

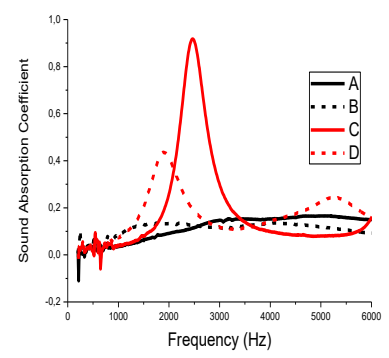

(a)

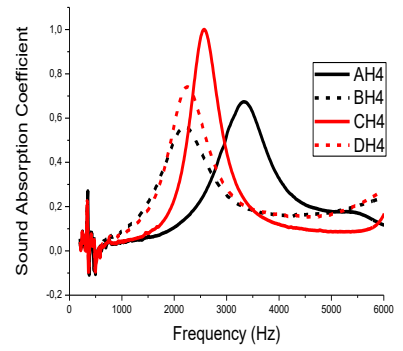

(b)

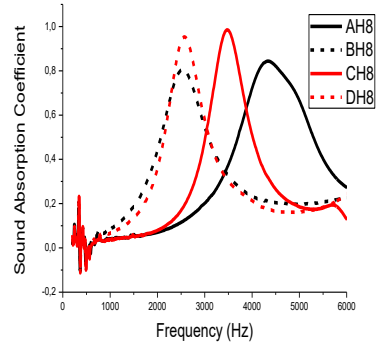

(c)

Fig. 2. Influence of resonator number on the sound absorption

It is clear from the results in figure (2) that water hyacinth based FRP is more reflected compared to the coconut husk based FRP. It happened because of the difference in the fiber size of the both materials. Water hyacinth has a smaller dimension and finer fiber compared to the one of coconut husk. As it mixed and blended with polymer and catalyst, the entire inter-fiber spaces are fully loaded with the mixture of polymer and catalyst. The resulted in FRP becoming more compact and dense. It explains why the water hyacinth based FRP sound absorption performance is lower than FRP made of coconut husk fiber.

The influence of resonance mechanism illustrated very clear in figure (2b) and (2c). It all agreed with the theoretical base that the longer resonator is resulting the lower resonant frequency. It causes the sound absorption performance shifted to the lower frequency band. As the number of resonators increased, the sound absorption tends to shifted to little bit 
higher frequency band, and the sound absorption coefficient value also increased. This phenomenon occurred as the viscous damping also occurred on the entire four test samples according to the resonators small diameter. The sound absorption performance in the higher frequency range gained accordingly. Typical of the air cavity and front porous layer impact on the sound absorption performance of the both water hyacinth (A) and coconut husk (C) based FRP illustrated in figure (3).

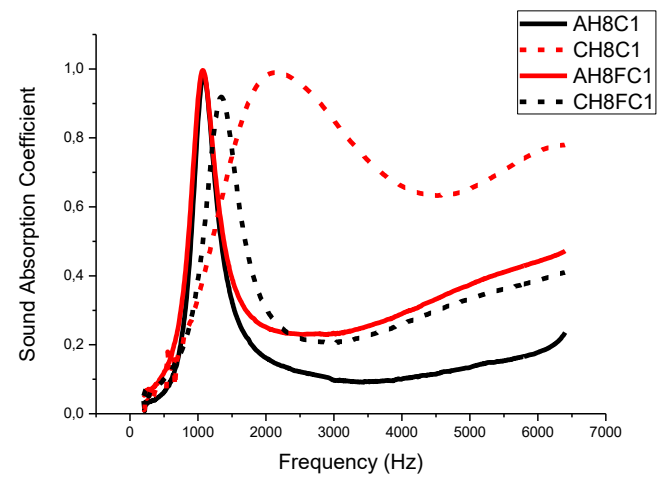

Fig. 3. Back cavity and front porous layer effect on the sound absorption

Helmholtz resonance mechanism occurs on both FRP as it coupled with an air cavity. The sound absorption coefficient reaches its best value of 0.98 on $1 \mathrm{kHz}$ for the water hyacinth and 0.95 for the coconut husk on the frequency $1.2 \mathrm{kHz}$. Since the geometrical dimension of the air cavity is similar for the entire test samples, the sound absorption shifted to the almost similar frequency as well. The water hyacinth based FRP perform on the lower frequency due to its internal structure which is denser compared to FRP made of coconut husk fiber. According to its soft structure, the coconut husk based FRP brings significant advantage as the front porous layer attached to the cavity backed $\mathrm{CH} 8 \mathrm{C} 1$. As seen on the graph, the test sample $\mathrm{CH} 8 \mathrm{FC} 1$ has a very promising broadband sound absorption profile. In this case, viscous damping associated with the porous and fibrous structure on the front layer occurs simultaneously with the resonance damping mechanism. When the back cavity is attached to the FRP that has an array of quarter wavelength resonators on it, the coupled structure response changes accordingly. It is becoming a new structure that works as a multiple neck Helmholtz resonator covered by porous and fibrous front layer. In the same time, the entire necks of the new coupled structure also have its frequency response as an array of half wavelength resonators. It explains why the sound absorption coefficient has an almost full spectrum profile and it shifted to the little bit higher frequency band compared to the sample test $\mathrm{CH} 8 \mathrm{C} 1$. The entire finding in this work proofs the advantages of natural fiber reinforced polymer panel made of natural resources. Natural fiber resources such as water hyacinth and coconut husk have a very potential economic value. It can be use as the raw materials of the high-performance, sustainable sound absorbing panel for various and wide range of noise control applications.

\section{Conclusion}

The cavity backed natural fiber reinforced polymer panel (NFRP) composite made of water hyacinth, and coconut husk has the valuable possibility for replacing the synthetic fiber composite mainly for building noise control applications. Broadband and high-performance sound absorber are very possible to make in the form of coupled structure where Helmholtz and half wavelength resonance occurred simultaneously with the viscous damping. Coconut 
husk based FRP is most powerful compared to the one of water hyacinth. The discrepancies on the ability to absorb sound waves energy mostly associated with geometrical size and mechanical properties fiber structure of the materials. Water hyacinth has the smaller geometrical dimension, and as it mixed with the polymer and catalyst, it is resulting in a denser and reflecting FRP panel.

This research funded by the Diponegoro University Research Grant Number: 27647/UN7.5.1/PG/2017 and partially supported by The Iwany Acoustics Research Group (iARG) of Sebelas Maret University especially on the laboratory test process. The funding institution does not have any intervention on the entire works. The authors would like to thanks to all colleagues and students and collaborating partners for their valuable supports.

\section{References}

1. E. Setyowati, E. E. Pandelaki, and E. Supriyo, JST (to be published).

2. M. H. Fouladi, M. Jailani, and M. Nor, Appl. Acoust., 72, 35-42 (2011).

3. J. Ramis, R. Rey, J. Alba, L. Godinho, and J. Carbajo, Matriales de Construccions. March, (2014).

4. J. Lee, and G. W. Swenson, NCE.. 38, 109-117 (1992).

5. R. Zulkifli, M. J. M. Nor, M. F. M. Tahir, A. R. Ismail, and M. z. Nuawi, J. Appl. Sci., 20, 3709-3714 (2008).

6. F. C. Lee and W. Chen, J. Sound Vib., 248, 621-634 (2001).

7. S. Ersoy and H. Kucuk, Appl. Acoust., 70, 215-220 (2009).

8. A. K. Mohanty, A. Wibowo, M. Misra, and L. T. Drzal, Composites, 35, 363-370 (2006).

9. D. H. Mueller and A. Krobjilowski, J. Ind. Text., 33, 111-130 (2003).

10. ASTM E 1050-98, Standard test method for Impedance and absorption of acoustical materials using tube two microphones and digital frequency analysis system. (1998). 